\title{
Avaliação Pós-Ocupação em Sistemas Construtivos Inovadores: Considerações Finais
}

\author{
Sheila Walbe Ornstein \\ Márcio Minto Fabricio \\ Rosaria Ono \\ Fabiana Lopes de Oliveira \\ Mena Cristina Marcolino Mendes \\ Lucas Melchiori Pereira \\ Miguel Antonio Buzzar
}

\section{A APO e a Avaliação Integrada de Desempenho de Sistemas Construtivos}

O histórico de inovaçóes tecnológicas observado na indústria da construção civil brasileira é orientado para a redução de custos e agilidade na produção das edificações (REZENDE; BARROS; ABIKO, 2002). Essas inovaçôes são muitas vezes adotadas em detrimento de melhorias nas condiçôes de uso e manutenção das edificaçôes produzidas (BONIN, 1998). O conflito entre os interesses de produção e a qualidade do produto está presente, particularmente na produção de Habitaçóes de Interesse Social, na qual programas governamentais, como o Minha Casa Minha Vida - MCMV, ou o programa da Companhia de Desenvolvimento Habitacional e Urbano CDHU, do Estado de São Paulo, subsidiam habitaçôes padronizadas de baixo custo para uma população de baixa renda.

Apesar do avanço institucional representado pelo SiNAT/PBQpHabitat/Ministério das Cidades, algumas lacunas importantes ainda foram verificadas. A primeira delas está relacionada à adequação do SiNAT à Norma Técnica NBR 15575 - Edificaçôes Habitacionais - Desempenho (ABNT, 2013) e aos novos parâmetros de desempenho impostos à produçáo 
habitacional brasileira. Uma segunda questão importante gira em torno do fato de os procedimentos do SiNAT estarem predominantemente vinculados à realização de ensaios técnicos para avaliação da segurança e desempenho dos componentes e do sistema construtivo em laboratório; assim, ainda é dada pouca atenção ao sistema construtivo em uso real e à percepção dos usuários sobre o seu desempenho.

O conteúdo deste capítulo se refere a uma parte do projeto que desenvolveu uma metodologia para a avaliação de desempenho em uso de sistemas construtivos inovadores, tendo como procedimentos metodológicos básicos aqueles preconizados na Avaliação Pós-Ocupação - APO. Apresenta conclusôes e consideraçôes sobre o projeto, cujos resultados da aplicação dos instrumentos em campo são apresentados nos Capítulos 8 a 10.

Desde os anos 1980, a APO vem sendo desenvolvida no Brasil do ponto de vista metodológico, com foco acadêmico. O principal estudo de caso abordado ao longo desse período, sobretudo no âmbito dos Programas de Pós-Graduação e de Graduação das Escolas de Arquitetura e Urbanismo e de Engenharia de Universidades públicas, é o da Habitação de Interesse Social - HIS (ROMÉRO; ORNSTEIN, 2003; ORNSTEIN; ONO, 2010). Isso se deve ao imenso parque habitacional destinado à população de baixa renda, construído por meio de programas habitacionais públicos nas cidades brasileiras de porte médio e grande, a maioria dos quais apresentando baixa qualidade construtiva. Trata-se de um processo histórico que vem ocorrendo nos últimos 40 anos (BONDUKI, 2014) e que na última década é fortemente impactado pelo volume de produção do programa federal Minha Casa, Minha Vida (BRASIL, 2016b). Tal programa representa alguns avanços em termos de acesso a diferentes faixas de baixa renda, mas continua operando na lógica histórica de produção em massa de habitações padronizadas, com forte expansão e impacto nas periferias das cidades (CARDOSO, 2013; CARVALHO; SHIMBO; RUFINO, 2015), afora sua lógica operacional, na maioria das vezes, seguir uma ótica empresarial (SHIMBO, 2012).

Diversos autores têm apontado a necessidade de revisão do processo de projeto a partir de um conhecimento mais profundo sobre o desempenho em uso desses empreendimentos habitacionais, com destaque para a verificação do ponto de vista e da percepção do usuário morador (KOWALTOWSKI; GRANJA, 2011; BONATTO; MIRON; FORMOSO, 2011; BERR et al., 2015; MONT'ALVÃO; VILLAROUCO, 2011). Em que pese o grande avanço dos estudos e pesquisas sobre APO em termos de procedimentos 
metodológicos, tendo-se em mente a qualidade no processo de projeto, produção, uso, operação e manutenção de ambientes construídos, especialmente no caso da habitação social (ABIKO; ORNSTEIN, 2002; FABRICIO; ORNSTEIN, 2010; ORNSTEIN; ONO, 2010; RHEINGANTZ et al., 2009; VILLA; ORNSTEIN, 2013; VILLA; SARAMAGO; GARCIA, 2015; LAY; REIS, 2005), pouco dessa expertise foi efetivamente aplicada às políticas públicas e à prática profissional no âmbito habitacional no Brasil, como ocorreu em outros países (MOHIT; NAZYDDAH, 2011; JANSEN, 2012). Nessa perspectiva, uma parte do projeto INOVATEC-FINEP se propóe a fazer uma ponte metodológica entre os instrumentos de APO específicos para a avaliação em uso de conjuntos habitacionais produzidos com sistemas construtivos inovadores e aqueles instrumentos aplicados de forma mais convencional, nas últimas décadas (FABRICIO, ONO, 2015).

A relevância desse tipo de avaliação (APO) com desdobramentos (diagnósticos e recomendaçôes) em todas as etapas da produção e da manutenção e operação das edificaçôes, desde a realimentação das atividades pré-projeto (edificaçôes e empreendimentos semelhantes) até a gestão (uso, operação e manutenção) dos empreendimentos em uso, já foram reiteradamente enfatizadas por autores como Finch (2012), Lawson (2011), Mallory-Hill, Preiser e Watson (2012) e Weilin et al. (2013).

Martucci e Basso (2002) apresentam especificamente o estudo pioneiro de Avaliação de Desempenho e Pós-Ocupação em sistemas construtivos inovadores, a partir de uma visão integrada, que considera o processo de produção, o uso e a inserção urbana desses sistemas. O projeto INOVATECFINEP colaborou com o desenvolvimento de um método integrado de avaliação, composto por instrumentos padronizados (checklists para vistorias técnicas, roteiros para entrevistas, formulários para questionários e outros), na medida em que promoveu o debate sobre os instrumentos com especialistas, em um ambiente interdisciplinar, e aplicou pré-testes a partir dos quais os instrumentos foram aprimorados, em um procedimento de "meta-avaliação" (ONO et al. 2015), bem como procurou inovar ao máximo os procedimentos de levantamento de campo. Exemplo disso foi a aplicação de questionários aos moradores por meio do uso de tablets para a racionalização dessa etapa da pesquisa.

À luz dos requisitos determinados pela NBR 15575 (ABNT, 2013), foi desenvolvido um sistema dedicado à realização de Avaliações Pós-Ocupação (APO), que parte da experiência obtida na aplicação e desenvolve recursos 
específicos para a avaliação. O desenvolvimento desse sistema contou com o apoio dos recursos da FINEP, dentro do projeto INOVATEC. O sistema dedicado é mais específico para realização de APO e poderá ser disponibilizado gratuitamente para Instituiçôes de Avaliação Técnica - ITA/ SiNAT, ou pesquisadores interessados.

As avaliaçóes técnicas no âmbito do Sistema Nacional de Avaliação Técnica de Sistemas Inovadores e Convencionais - SiNAT, são de grande importância para garantir padróes mínimos de segurança e qualidade aos usuários dos sistemas construtivos. Porém, é preciso admitir que a habitação se configura em uma forte interação entre usuário, sistema construtivo, projeto e cidade. Assim, o desempenho durante o uso também deve ser acompanhado e avaliado com o objetivo de compreender o comportamento, as necessidades e expectativas dos usuários/moradores em relação à moradia. Nesse contexto, a Avaliação Pós-Ocupação é entendida como uma etapa de gestão da qualidade do processo de projeto por considerar a visão do usuário e do especialista, com o objetivo de subsidiar programas de manutenção, uso e operação (ORNSTEIN; ONO; OLIVEIRA, 2017).

O grande desafio desta pesquisa foi propor um conjunto de instrumentos de Avaliação Pós-Ocupação que pudesse contribuir para o aprimoramento do método de avaliação de sistemas construtivos inovadores, considerando o desempenho das edificaçôes habitacionais ao longo de sua vida útil, durante seu período de uso/ocupação, na qual sofre manutençôes preventivas e corretivas, assim como adequações às necessidades dos usuários (ampliações e reformas).

Esse desafio é particularmente complexo porque o desempenho em uso depende da interação entre sistema construtivo, projeto da unidade habitacional e seu uso. Assim, os resultados de uma APO não podem ser associados direta e unicamente ao desempenho do sistema construtivo, sendo resultado acumulado de várias etapas do ciclo de vida da unidade. Entretanto, os procedimentos metodológicos de $\mathrm{APO}$ propostos permitem avaliar a interação do sistema construtivo em uso real e apontar questóes para serem avaliadas e, eventualmente, investigadas em profundidade pelas ITAs responsáveis pelo acompanhamento do sistema construtivo. Assim, a abordagem metodológica proposta complementa o sistema de avaliação técnica vigente, estendendo a avaliação para fase de uso e operação do sistema construtivo.

Os procedimentos aqui mencionados compreenderam seis instrumentos integrados de pesquisa, conforme a Figura 1, a seguir. 


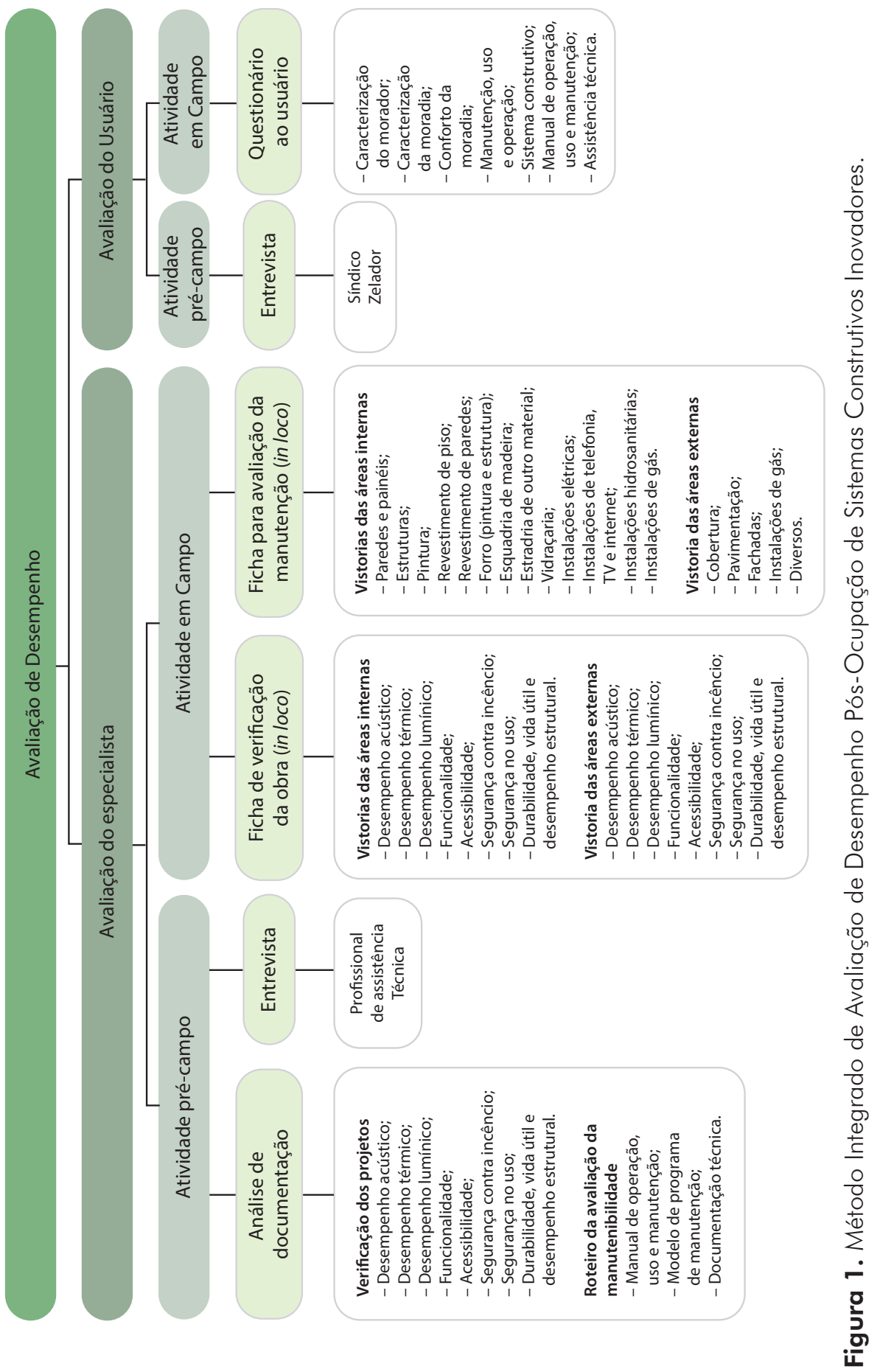


Os instrumentos retratados na figura anterior, com exceção das entrevistas com síndico/zelador, que não foram realizadas porque $\mathrm{o}$ empreendimento estudado não estava constituído como condomínio, foram aplicados em um estudo de caso, cujos resultados foram apresentados nos capítulos 8 a 10 e a partir do qual foi possível concluir principalmente que:

- Os instrumentos, em geral, cumpriram o seu papel, permitindo uma avaliação compreensiva do desempenho das unidades habitacionais;

- Há um número considerável de itens de avaliação que são marcados como náo se aplicam ao estudo de caso, devido às características construtivas e organizacionais do empreendimento. Fato que reforça a necessidade de adequar todos os instrumentos de avaliação a cada estudo de caso;

- Recomenda-se que outros sistemas construtivos no âmbito do SiNAT/ PBQpHabitat sejam testados com esses instrumentos avaliativos, para verificar as peculiaridades construtivas encontradas em outros campos de pesquisa e em contextos regional, climático e cultural diferentes, a fim de ampliar as discussôes sobre a necessidade de refinamento do método ou elaborar um formato adaptado para cada caso específico;

- Percebe-se que seria mais adequado dividir os instrumentos entre aqueles destinados a empreendimentos horizontalizados (residências unifamiliares) e aqueles relativos a empreendimentos verticalizados, já que as áreas comuns, em cada caso, são bastante distintas;

- Os profissionais, para aplicar a avaliação, deverão receber manual explicativo dos procedimentos a serem adotados em campo, tanto no contato com as pessoas chave e com os moradores, como nas vistorias técnicas. Além disso, seria oportuna a realização de capacitação técnica com vistas à realização de tal atividade. Esse treinamento poderia ser presencial ou à distância e deveria ter curto prazo;

- Há falhas na apresentação das documentações técnicas para avaliação do projeto e da manutenibilidade das unidades habitacionais. A documentação fornecida foi insuficiente em muitos casos, dificultando a aplicação de outros instrumentos por falta de informaçóes sobre o sistema construtivo e detalhes do projeto, assim como sobre os procedimentos de manutenção;

- As respostas dos moradores quanto aos problemas construtivos (manifestaçóes patológicas) encontrados na unidade habitacional reforçam os resultados das avaliaçóes "in loco" realizadas pelos especialistas. No entanto, é relevante destacar a importância do contato com os moradores, seja durante a aplicação do questionário ou da avaliaçấo "in loco", pois importantes informaçôes de usuários foram registradas pelos especialistas nessas ocasióes; 
- Dos problemas encontrados no caso analisado, em particular, muitos são falhas sistemáticas geradas, aparentemente, pela baixa qualidade de alguns elementos construtivos empregados na habitação, como as esquadrias metálicas, as portas internas de madeira e o piso cerâmico nos banheiros. O sistema construtivo em si é robusto e apresentou poucas falhas sistemáticas;

- Os sistemas convencionais não são objetos de avaliação técnica, exceto as interfaces desses sistemas com o inovador, devendo-se conferir a essa interface uma maior atenção durante o projeto e a execuçáo;

- Uma das questóes levantadas pelos moradores se refere ao conforto térmico, pois a regiáo em que o empreendimento está implantado apresenta temperaturas elevadas em grande parte do ano. No entanto, a documentação de projeto e da análise de desempenho do sistema construtivo é satisfatória em relação a esse requisito. Desta forma, observa-se que possivelmente os critérios de conforto térmico não estejam adequados para a regiáo em questáo;

- A orientação e a implantação dos empreendimentos não são preocupação ou responsabilidade da empresa construtora/proponente, visto que náo se trata de um pré-requisito solicitado pela Companhia contratante do sistema construtivo. Entretanto, deve ser um requisito a ser fortemente considerado com intuito de favorecer o conforto térmico nas habitaçôes;

- Verificou-se que o perfil dos moradores é muito variado, porém as famílias em geral não são numerosas. No entanto, parece haver uma incompatibilidade entre o projeto e as necessidades dos moradores. Os próprios moradores questionaram as pequenas dimensōes do terceiro dormitório, muitas vezes utilizado como depósito, e se mostraram também pouco satisfeitos quanto à dimensão reduzida da cozinha. Desta forma, verifica-se que oferecer um dormitório adicional náo parece ser a melhor soluçáo de projeto para garantir o bem-estar e a satisfação dos moradores com a residência;

- A utilização inadequada da instalação de gás é um problema grave, porém, aparentemente, decorre da falta de informação de muitos dos moradores sobre o funcionamento do sistema. Por outro lado, vários moradores levantaram outras questôes relativas a esse item, como o risco de furto dos botijóes deixados no abrigo ou a posição da saída do gás, ao lado da porta, considerada inadequada para o uso do fogáo (a chama se apaga com o vento e aumenta o consumo);

- Não há, ainda, entre os moradores, a cultura da manutenção preventiva e também o cuidado na leitura e conservação do Manual de Uso, Operação e Manutenção da edificação. Verificou-se que poucos deram importância ao Manual, assim como quase nenhum morador realiza manutenção preventiva; 
- Considera-se como procedimento essencial a adoção por parte dos moradores dos conteúdos do Manual de Uso, Operação e Manutençấo, com vistas à durabilidade da edificação e de seu sistema construtivo como um todo. Assim, o Manual deve apresentar sempre informaçôes técnica corretas, porém de forma bastante amigável e acessível; sobretudo, em relaçáo à funcionalidade dos ambientes e às futuras adaptaçôes, que são pouco detalhadas no Manual do Proprietário;

- O serviço de Assistência Técnica foi mal avaliado e verificou-se que não há clareza, entre os moradores, de como acionar esse serviço, havendo uma responsabilidade difusa entre as partes envolvidas (Governo Estadual, Prefeitura e Construtora);

- O não recebimento da Assistência Técnica é agravado pela perda da garantia, seja pelo tempo de uso da casa ou de modificaçôes, seja devido a adaptaçôes e ampliaçóes feitas pelo morador;

- O empreendimento é notório pela tecnologia construtiva empregada, reconhecida pelos moradores, porém não fornece segurança patrimonial, privacidade, limpeza pública e equipamentos comunitários condizentes;

- A gestão dos espaços comunitários e o fortalecimento das associaçóes de bairro como uma extensão do serviço social prestado pelo serviço público poderiam melhorar a adaptação dos moradores ao local;

- A recomendação é de que a $\mathrm{APO}$ deve ser aplicada ao menos no empreendimento habitacional piloto com sistema construtivo inovador e, por amostragem, periodicamente nos empreendimentos habitacionais subsequentes implantados com o mesmo sistema, como procedimento de gestão e monitoramento da qualidade

\section{Considerações Finais}

Há a necessidade de avaliação continuada de políticas públicas para o incremento da qualidade das habitaçóes e dos empreendimentos. Como exemplos de procedimentos metodológicos para a implementação de avaliaçóes no caso do PMCMV, tem-se os estudos de Villa, Saramago, Garcia (2015) e Carvalho, Shimbo e Rufino (2015). Tais pesquisas, porém, são limitadas em relação ao tempo, pois não há um balanço amplo sobre os programas habitacionais colocados em prática nos últimos 12 ou 13 anos. Algumas conclusôes podem ser obtidas a partir do balanço realizado para a Faixa 1 (até 3 salários-mínimos) do PMCMV pelo Ministério da 
Transparência, Fiscalização e Controladoria-Geral da União (BRASIL, 2016a).

É fundamental a aplicação de APOs em empreendimentos-piloto que empregam sistemas construtivos chamados inovadores, antes da construção em escala. Implementaçóes-piloto deveriam existir, em fase anterior, para que sejam viáveis os aperfeiçoamentos no sistema construtivo, nas condições de conforto ambiental, de segurança, funcionalidade e acessibilidade, antes da replicação da mesma tipologia arquitetônica, construtiva e urbanística em um formato padronizado nas distintas regiôes do país. Os pareceres das ITAs no SiNAT hoje analisam, essencialmente, os projetos dos sistemas construtivos por meio de uma avaliação pré-projeto, porém o presente trabalho objetivou demonstrar que a APO pode oferecer informaçóes relevantes sobre a qualidade do projeto sob o ponto de vista do desempenho em uso.

As políticas habitacionais deveriam considerar uma melhor integração entre o projeto de urbanização da área e a implantação da unidade no lote. Todos os agentes deveriam participar do processo, desde os projetistas, o fabricante/construtor do sistema construtivo inovador e das unidades habitacionais e, também, aqueles responsáveis pela urbanização. Moradia e cidade devem ser pensadas de forma conjunta, sem a ruptura verificada entre a unidade habitacional e o lote e entre o lote e a quadra/cidade.

Esta pesquisa procurou trazer contribuições no sentido de otimizar também a implementação de fichas de verificação acerca do desempenho físico das unidades habitacionais e promover a facilitação da aplicação de questionários junto aos moradores para medição de satisfação por meio de uso de tablets e de aplicativos, gerando rotinas para simplificar a aplicaçáo de APO por profissionais treinados em empreendimentos que envolvam sistemas construtivos inovadores.

A pesquisa ainda demonstrou que as fichas de verificação sobre o desempenho das unidades/empreendimentos, assim como os questionários para medição de satisfação dos usuários, devem permitir alguma flexibilidade quanto a temas e tópicos a serem incorporados, já que contextos urbanos, empreendimentos e sistemas construtivos das unidades, com muita frequência, apresentam diferenças entre si.

Entende-se que, para a Avaliação Pós-Ocupação, deve-se proceder a (1) análise dos documentos e projetos arquitetônicos e urbanísticos, seguidas 
de (2) entrevistas com pessoas chaves, como o arquiteto, o profissional de assistência técnica, os responsáveis técnicos dos gestores públicos envolvidos (estaduais e municipais, por exemplo), e síndicos e ou líderes comunitários locais, as quais devem ser o ponto de partida para o planejamento das açóes relativas ao levantamento de campo. Já o levantamento de campo, se possível, deve ter início com a (3) aplicação das fichas de vistorias técnicas. Os subsídios técnicos extremamente bem fundamentados, obtidos a partir dos itens anteriores (1), (2) e (3), fornecerão forte respaldo para a (4) aplicação dos questionários e seus eventuais ajustes em relação à versão padrão.

Entende-se ainda que os procedimentos de APO aqui recomendados são aqueles essenciais (mínimo) para a avaliação de desempenho em uso de empreendimentos com as características indicadas nesta pesquisa.

\section{Referências}

ASSOCIAÇÃO BRASILEIRA DE NORMAS TÉCNICAS - ABNT. NBR 15575: Edificaçôes Habitacionais - Desempenho Partes 1 a 5. Associação Brasileira de Normas Técnicas. Rio de Janeiro. 2013.

ABIKO, A.K.; ORNSTEIN, S.W. (Orgs.). Inserção Urbana e Avaliaçáa Pós-Ocupaçáo (APO) da Habitação de Interesse Social. São Paulo: Faculdade de Arquitetura e Urbanismo da Universidade de Sáo Paulo/Associaçáo Nacional de Tecnologia do Ambiente Construído, 2002. 373p. Diponível em: http://www.habitare.org.br/pdf/ publicacoes/arquivos/92.pdf . Acesso em: 9 jan. 2017.

BERR, L.R. et al. Indicador de falhas de qualidade baseado na percepçáo dos usuários de habitação de interesse social. Ambiente Construído. Porto Alegre: ANTAC, v. 15, n. 4. 2015. pp. 19-35. Disponível em http://seer.ufrgs.br/index.php/ambienteconstruido/ article/view/54219. Acesso em: 9 jan. 2017.

BONATTO, F.S.; MIRON, L.I.G.; FORMOSO, C.T. Avaliação de empreendimentos habitacionais de interesse social com base na hierarquia de valor percebido pelo usuário. Ambiente Construído (Online), v. 11, p. 67-83, 2011. Disponível em: http://www. scielo.br/pdf/ac/v11n1/a06v11n1.pdf. Acesso em: 2 abr. 2017.

BONDUKI, N.G. Pioneiro da habitaçáo social. Cem anos de construção de política no Brasil. São Paulo: Editora UNESP e Ediçóes SESC. 2014. 387p

BONIN, L.C. Consideraçóes sobre a utilizaçáo do conceito de desempenho como instrumento para a modernização tecnológica na construção de edificaçôes. Encontro Nacional de Tecnologia do Ambiente Construído, 7º. Anais... Florianópolis: [s.n.]. 1998. 
BRASIL. Ministério da Transparência, Fiscalização e Controladoria-Geral da União. Relatório de Avaliaçáo da Execuçáo de Programa de Governo No 65 - Integralização de Cotas ao Fundo de Arrendamento Residencial - FAR (PPA 2011/2015). Brasília, 2016 a.

CARDOSO, A.L. (Org.) O programa Minha Casa Minha Vida e seus efeitos territoriais/Adauto Lucio Cardoso (org.). Rio de Janeiro: Letra Capital, 2013. 322 p.

CARVALHO, C.S.A.; SHIMBO, L.Z.; RUFINO, M.B.C. (Orgs.). Minha casa... e a cidade? Avaliação do Programa Minha Casa Minha Vida em seis estados brasileiros. 1. ed. Rio de Janeiro: Letra Capital, 2015. v. 1. 428p .

FABRICIO, M.M.; ONO, R. (Orgs.). Avaliação de Desempenho de Tecnologias Construtivas Inovadoras: Manutenção e Percepção do Usuário. Porto Alegre: ANTAC/ Caboverde, 2015. v. 1, 159 p. DOI: http://dx.doi.org/10.4322/978-85-89478-42-7

FABRICIO, M.M.; ORNSTEIN, S.W. Qualidade no Projeto de Edifícios. São Carlos: RIMA, ANTAC, 2010. 261p.

FINCH, E. (ed.). Facilities Change Management. UK: Wiley-Blackwell, 2012. 202p.

JANSEN, S.J.T. Why is Housing Always Satisfactory? A Study into the Impact of Preference and Experience on Housing Appreciation. Social Indicators Research, v. 113, n. 3, pp. 785-805, 2012. DOI: http://dx.doi.org/10.1007/s11205-012-0114-9.

KOWALTOWSKI, D.C.C.K.; GRANJA, A.D. The concept of desired value as a stimulus for change in social housing in Brazil. Habitat International, v. 35, n. 3, pp. 435-446, jul. 2011.

LAY, M.C.; REIS, A. Análise quantitativa na área de estudos ambiente-comportamento. Ambiente Construído, Porto Alegre, v. 5, n. 2, pp. 21-35, abr./jun. 2005.

LAWSON, B. Como arquitetos e designers pensam. São Paulo: Oficina de Textos, 2011. 296p.

MALLORY-HILL, S.; PREISER, W.F.E.; WATSON, C. Enhancing Building Performance (eds.). UK: Wiley-Blackwell, 2012. 330p.

MARTUCCI, R.; BASSO, A. Uma visão integrada da análise e avaliação de conjuntos habitacionais: aspectos metodológicos da pós-ocupação e do desempenho tecnológico. In: ABIKO, A.K; ORNSTEIN, S.W. (eds.) Inserção Urbana e Avaliação Pós-Ocupação (APO) da habitaçáo de interesse social. São Paulo: FAUUSP, 2002. (Coletânea Habitare/ Finep, 1), p. 269-293.

MOHIT, M.A.; NAZYDDAH, N. Social housing programme of Selangor Zakat Board of Malaysia and housing satisfaction. Journal of Housing and the Built Environment, v. 26, n. 1, pp. 123-142, 2011. http://www.jstor.org/stable/41261676. Acesso em: 2 jul., 2017.

MONT'ALVĀO, C.; VILLAROUCO, V. (Orgs.). Um novo olhar para o projeto. A ergonomia no ambiente construído. Teresópolis, RJ: 2AB, 2011. 183p. 
ONO, R. et al. Avaliação Pós-Ocupação: pré-teste de instrumentos para verificação do desempenho de empreendimentos habitacionais em sistema construtivos inovadores. Gestáo de Tecnologia \& Projeto. Sáo Carlos: Instituto de Arquitetura e Urbanismo da Universidade de São Paulo. v. 10, n. 1, 2015. pp. 64-78. DOI: http://dx.doi. org/10.11606/gtp.v10i1.88979

ORNSTEIN, S.W.; ONO, R.; OLIVEIRA, F.L. Em busca da qualidade na habitação social no Brasil: instrumentos para a Avaliação Pós-Ocupação (APO) aplicada a sistemas construtivos inovadores. Anais... $4^{\circ}$ CONGRESSO INTERNACIONAL DA HABITAÇÃO NO ESPAÇO LUSÓFONO. Covilhã, Universidade Beira Interior, 2017. p. 49-60.

ORNSTEIN, S.W.; ONO, R. Post-Occupancy Evaluation and design Quality in Brazil: concepts, approaches and an example of application. Architectural Engineering and Design Management. v. 6, pp. 48-67, 2010.

REZENDE, M.A.P.D.; BARROS, M.M.S.B.D.; ABIKO, K. Barreiras e facilitadores da inovação tecnológica na produção de habitaçóes populares. in: Encontro Nacional de Tecnologia no Ambiente Construído Artigo Técnico, 9. Foz de Iguaçu. Anais... ENTAC. 2002. p. 895-904. Disponivel em: http://www.iau.usp.br/pesquisa/grupos/arquitec/ entac/2002/Artigos/ENTAC2002_0895_904.pdf. Acesso em: 25 out. 2014.

RHEINGANTZ, P.A. et al. Observando a qualidade do lugar. Procedimentos para a Avaliação Pós-Ocupação. Rio de Janeiro: PROARQ, FAU UFRJ, 2009. 117p. Disponível em: http://www.gae.fau.ufrj.br/assets/obs_a_qua_lugar.pdf. Acesso em: 2 jul. 2017.

ROMÉRO, M.A.; ORNSTEIN, S.W. Avaliação Pós-Ocupação. Métodos e Técnicas aplicados na Habitaçáo Social. Porto Alegre: Associação Nacional de Tecnologia do Ambiente Construído, 2003. 294p. Disponível em: www.habitare.org.br/publicacao_ colecao1.aspx. Acesso em: 9 jan. 2017.

SHIMBO, L. Habitaçao Social de Mercado: Confluência entre Estado, Empresas Construtoras e Capital Financeiro. São Paulo: C/Arte, 2012.

VILLA, S.B.; ORNSTEIN, S.W. Qualidade ambiental na habitação. Avaliação PósOcupação. São Paulo: Oficina de Textos, 2013. 400p.

VILLA, S.B.; SARAMAGO, R.C.P.; GARCIA, L.C. Avaliação Pós-Ocupação no Programa Minha Casa MinhaVida. Uma Experiência Metodológica. Uberlândia: Universidade Federal de Uberlândia. 2015. Disponível em: https://morahabitacao.files.wordpress.com/2015/07/ os-014631-proex-ufu-livro-sangria-lu.pdf. Acesso em: 17 nov., 2016.

WEILIN, S. et al. The user pre-occupancy evaluation method in designer - client communication in early design stage: A case study. Automation in Construction. v. 32, july 2013. pp. 112-124. Disponível em: http://www.sciencedirect.com/science/article/ pii/S0926580513000241. Acesso em: 16 abr. 2017.

\section{Sites consultados}

BRASIL. Programa Minha Casa Minha Vida. Disponível em: www.minhacasaminhavida. gov.br. 2016b. Acesso em: 22 dez. 2016. 